\title{
Características físico-químicas y microbiológicas del compostaje de bagazo de agave tequilero a escala industrial
}

\section{Physico-chemical and microbiological characteristics of large scale tequila agave bagasse composting}

CRESPO-GONZÁLEZ, Marcos Rafael†*， RODRÍGUEZ-MACÍAS， Ramón, GONZÁLEZEGUIARTE, Diego Raymundo y CANALE-GUERRERO, Alejandro

Universidad de Guadalajara. Centro Universitario de Ciencias Biológicas y Agropecuarias, Camino Ramón Padilla Sánchez 2100, Nextipac, 44600, Zapopan, Jalisco, México.

ID $1^{\text {er }}$ Autor: Marcos Rafael, Crespo-González / ORC ID: 0000-0002-0675-4140, Researcher ID Thomson: T-4524-2018, CVU CONACYT ID: 236808

ID $1^{\text {er }}$ Coautor: Ramón, Rodríguez-Macías / ORC ID: 0000-0003-0857-6699, Researcher ID Thomson: W-9275-2019, CVU CONACYT ID: 35267

ID $2^{\text {do }}$ Coautor: Diego Raymundo, González-Eguiarte / ORC ID: 0000-0001-6609-0780, Researcher ID Thomson: T-45552018, CVU CONACYT ID: 4475

ID $3^{\text {er }}$ Coautor: Alejandro, Canale-Guerrero / ORC ID: 0000-0001-6139-9463, PubMed Autor ID: CAS- 415356B1Q0M9, CVU CONACYT ID: 35267

DOI: 10.35429/JCPE.2019.21.6.25.34 Recibido 09 Agosto, 2019; Aceptado 30 Noviembre, 2019

\section{Resumen}

Este estudio tuvo el objetivo de evaluar algunas características físico-químicas que ocurren durante el proceso de compostaje a escala industrial de bagazo de agave tequilero, así como cuantificar la dinámica poblacional de bacterias, hongos y actinomicetos durante 300 días. Se estableció una pila de bagazo de agave de aproximadamente $195 \mathrm{~m}$ de longitud ( 331 t), la cual fue composteada y monitoreada regularmente. Posteriormente se reubicó una parte para continuar la evaluación. Se tomaron muestras de la pila cada 15 días y se evaluó contenido de humedad, temperatura, $\mathrm{pH}$, conductividad eléctrica (CE), materia orgánica $(\mathrm{MO})$, relación $\mathrm{C} / \mathrm{N}$ y la dinámica poblacional de bacterias, hongos y actinomicetos en unidades formadoras de colonias. Desde el principio del compostaje la temperatura se mantuvo en el nivel termófilo $\left(>45{ }^{\circ} \mathrm{C}\right.$ ) hasta los 270 días y concluyó en $42{ }^{\circ} \mathrm{C}$ debido a la reducción de la humedad $(<30 \%)$. La CE llegó a un máximo de $1.5 \mathrm{dS} / \mathrm{m}$, la MO se mantuvo entre 70 - $35 \%$, y la relación $\mathrm{C} / \mathrm{N}$ varió entre 96.9 inicial y 29.6 final. Los actinomicetos fueron el grupo más dominante, especialmente en las últimas semanas del compostaje, lo cual infiere la posibilidad de usar este tipo de composta en la biorremediación de suelos.

Composta, Biodegradación, Residuos sólidos del tequila

\begin{abstract}
The aim of the present study was to evaluate some physicochemical characteristics of large scale composting process of tequila agave bagasse, and also quantify the population dynamic of bacteria, fungi and actinomycetes througout 300 days. A large windrow of agave bagasse of approximately $195 \mathrm{~m}(\sim 331 \mathrm{t})$ was set and regularly monitored. Thereafter a pile section was reubicated to continue the evaluation. The windrow was sampled every 15 days and the following parameters were measured: moisture content, temperature, $\mathrm{pH}$, electric conductivity (EC), the organic matter $(\mathrm{OM}), \mathrm{C} / \mathrm{N}$ ratio and the population dynamic of bacteria, fungi and actynomicetes in colony forming units. From the very beginning of composting the temperature of the windrow reached the thermophylic phase $\left(>45^{\circ} \mathrm{C}\right)$ and continued up to 270 days. However, at the end of the study the temperature felt down till $42{ }^{\circ} \mathrm{C}$ due to the reduction on moisture content $(<30 \%)$. The highest EC registered was $1.5 \mathrm{dS} / \mathrm{m}$; the OM remained between $70-35 \%$ and the $\mathrm{C} / \mathrm{N}$ ratio varied between 96.9 initial and 29.6 final. Actinomycetes were the most dominant group especially in the last weeks of composting, which infers the possibility of using this type of compost in soil bioremediation.
\end{abstract}

Compost, Biodegradation, Tequila solid residues

Citación: CRESPO-GONZÁLEZ, Marcos Rafael, RODRÍGUEZ-MACÍAS, Ramón, GONZÁLEZ-EGUIARTE, Diego Raymundo y CANALE-GUERRERO, Alejandro. Características físico-químicas y microbiológicas del compostaje de bagazo de agave tequilero a escala industrial. Revista de Energía Química y Física. 2019. 6-21: 25-34

\footnotetext{
* Correspondencia al Autor (Correo electrónico: marcos.crespo@academicos.udg.mx)

$\dagger$ Investigador contribuyendo como primer Autor
} 


\section{Introducción}

El bagazo de agave tequilero (Agave tequilana Weber. var. azul) es el residuo de la molienda de las cabezas cocidas de agave a las que se le extraen los jugos para ser fermentados. Según el Consejo Regulador del Tequila (CRT, 2019), el consumo de agave en 2018 fue de 1.14 millones de toneladas, de las cuales aproximadamente el $40 \%$ del peso total de las cabezas de agave es bagazo (Cedeño, 1995). El bagazo está compuesto principalmente por fibras de 10 a 12 $\mathrm{cm}$ de largo (haces fibrovasculares) y material no fibroso en forma de partículas finas y suaves llamado médula o parénquima (Iñiguez et al., 2007).

Alonso y Rigal (1997) consignan que la proporción de los componentes dominantes del bagazo son: celulosa (43\%), lignina $(15 \%)$ y hemicelulosa (19\%). Con respecto a sus características químicas, PROFOA (2010) reporta los resultados que se muestran en la Tabla 1, en donde destaca la alta relación $\mathrm{C} / \mathrm{N}$ (96.9) y elevado contenido de calcio $(3.31 \%$ M.S.).

Actualmente, varias empresas tequileras producen composta de bagazo, la producción a gran escala se realiza usando bagazo con el cual se forman pilas aireadas con maquinaria durante 120 a 150 días. En cuanto a estudios sobre la microbiología del compostaje de bagazo, únicamente Rodríguez et al. (2004) reportan una investigación realizada a escala piloto; a escala industrial no hay registros.

Dado que en el compostaje intervienen bacterias, hongos y actinomicetos, es importante caracterizar la dinámica de estos microorganismos y las condiciones ambientales en las que se desarrollan para entender mejor cómo ocurre el compostaje a gran escala, a fin de mejorar la eficiencia del proceso y las propiedades del producto final. En vista de lo anterior, el presente estudio tuvo como objetivo evaluar los parámetros físicos y químicos, así como la dinámica poblacional de bacterias, hongos y actinomicetos que ocurren durante el proceso de compostaje a gran escala de bagazo de agave tequilero.

\section{Materiales y Métodos}

El trabajo de campo se llevó a cabo en dos etapas y sitios diferentes. El primero ocurrió en el predio El Mundeño, localizado en Magdalena, Jalisco, con coordenadas geográficas $20^{\circ} 54^{\prime} 35^{\prime \prime}$ latitud Norte y 103 $50^{\prime} 11 "$ longitud Oeste; ubicado a $1,380 \mathrm{msnm}$ y aproximadamente a 20 $\mathrm{km}$ de la ciudad de Tequila, Jalisco. El segundo fue en el Rancho El Indio, propiedad de Tequila Sauza, S.A., localizado en Tequila, Jalisco, con coordenadas 20 $533^{\prime} 38^{\prime \prime}$ latitud Norte y 10350'11" longitud Oeste; ubicado a 1,180 msnm. El clima de la región es semiseco, con invierno y primavera secos, y semicálido sin estación invernal definida y una temperatura media anual de $23.2{ }^{\circ} \mathrm{C}$; presenta un régimen de lluvia entre los meses de junio a octubre con una precipitación media anual de 1,073.1 $\mathrm{mm}$ (INIFAP, 2005).

El bagazo de agave utilizado fue transportado desde la destilería La Perseverancia de la empresa Tequila Sauza, S.A., localizada en Tequila, Jal., hasta el sitio de compostaje. Las características del bagazo fueron las siguientes: a) Temperatura: $65-70{ }^{\circ} \mathrm{C}$, b) Humedad: $82 \%$, c) Relación C/N: 96.9 y d) Azúcares residuales: $12.3 \%$.

El estudio inició a partir de la formación completa de la pila de compostaje el día 11 de junio de 2008 y permaneció en el predio El Mundeño hasta el 9 de noviembre de 2008 (150 días), fecha en que se trasladó una parte al Rancho El Indio, en donde continuó el proceso hasta concluir el estudio el 21 de abril de 2009. Cabe hacer la aclaración que, aunque el compostaje en la empresa se lleva a cabo en 150 días, esta investigación se extendió a 300 días por el interés de conocer los límites del proceso en términos microbiológicos, físicos y químicos.

En el predio El Mundeño, se estableció una pila en forma de cordón de aproximadamente $3.0 \mathrm{~m}$ de ancho, $1.70 \mathrm{~m}$ de altura y $195 \mathrm{~m}$ de longitud, con un peso aproximado de 331 toneladas, equivalente a 278 $\mathrm{m}^{3}$. El 18 de junio de 2008, la pila fue inoculada con $300 \mathrm{~kg}$ de composta de bagazo (con 60 días de compostaje), por cada seis metros de longitud y se le aplicó el primer volteo utilizando una composteadora. El segundo volteo ocurrió el día 17 de julio, posteriormente, los volteos se realizaron una vez por semana hasta el día 9 de noviembre. 
A partir de esa fecha, en el Rancho El Indio, se estableció una pila de $2.50 \mathrm{~m}$ de ancho, $20.5 \mathrm{~m}$ de largo y $0.90 \mathrm{~m}$ de altura, de aproximadamente 16 toneladas $\left(\sim 20 \mathrm{~m}^{3}\right)$, realizando volteos cada 15 días, hasta finalizar el estudio. Los muestreos se realizaron a partir del 11 de junio del 2008 (día cero) y a partir de esa fecha se efectuaron con una periodicidad de 15 días, antes de cada volteo, hasta finalizar el estudio el día 21 de abril del 2009. En cada muestreo, la pila de composta se dividió en tres secciones, cada una de ellas de aproximadamente $65 \mathrm{~m}$ de longitud. Cada sección se subdividió a su vez en otras tres y en cada una se midió la temperatura con termómetro marca Rochester de carátula y con bayoneta, a $61 \mathrm{~cm}$ de profundidad sobre la parte superior de la pila y allí mismo se tomó una muestra de composta de aproximadamente $4 \mathrm{~kg}$. Con las tres muestras tomadas de cada sección se formó una muestra compuesta, para dar un total de tres muestras, a las cuales se les realizaron los análisis físicos, químicos $\mathrm{y}$ microbiológicos.

A las muestras de composta se analizó el contenido de humedad, materia orgánica (MO), ceniza, carbono orgánico total (COT), nitrógeno total Kjeldahl (NTK), conductividad eléctrica (CE), $\mathrm{pH}$ y las poblaciones de bacterias, hongos y actinomicetos. La humedad o materia seca se determinó al secar una muestra durante 24 horas a $105{ }^{\circ} \mathrm{C}$. Para el análisis de cenizas, la muestra se puso a la mufla a $550{ }^{\circ} \mathrm{C}$ por dos horas. El material volátil se consideró MO (AOAC, 1984). El pH y la CE se determinaron en extractos en agua; la relación peso/volumen fue de 1:5 (CWMI, 1996). El pH se midió con un potenciómetro marca Beckman y la conductividad con un conductímetro marca YSI.

El contenido de NTK se determinó por el procedimiento macro-Kjeldahl (AOAC, 1984). El COT se calculó mediante la siguiente ecuación (Golueke, 1977): \% COT = (100cenizas)/1.8. La relación $\mathrm{C} / \mathrm{N}$ se obtuvo a partir de los análisis anteriores de COT y NTK. En cuanto a la cuantificación de poblaciones de bacterias, hongos y actinomicetos se aplicó la técnica de cultivo en cajas de Petri sugerida por Robert (1990), con el cual se hace un recuento de las unidades formadoras de colonias (ufc $\mathrm{g}^{-1}$ M.S.) con los tiempos de incubación y medios específicos utilizados para cada grupo microbiano de acuerdo a Wollum (1982).
Finalmente, los azúcares residuales del bagazo se analizaron mediante la técnica descrita por Miller (1959). Los resultados fueron evaluados a través de un análisis de regresión no lineal y se utilizó el paquete estadístico Minitab ${ }^{\circledR}$ versión 17 (2015). Para el pH se aplicó el modelo de Gompertz; para la CE, el modelo recíproco cuadrático y para la humedad y la temperatura el modelo sinusoidal.

\section{Resultados y Discusión}

\section{Dinámica de la humedad}

En la Gráfica 1, se aprecia que la humedad de la pila se mantuvo en el intervalo adecuado hasta los 195 días, a este respecto, Bueno et al. (2008) consideran que la humedad ideal para el crecimiento microbiano está entre $50-70 \%$ y que la actividad biológica decrece cuando la humedad está por debajo del 30\%. La gráfica de regresión muestra que la pérdida de humedad es muy determinante con respecto al tiempo de compostaje $\left(\mathrm{R}^{2}=0.986\right)$. A 195 días de haber iniciado la degradación biológica existían aún buenas condiciones de humedad lo que propició una elevada temperatura $\left(49{ }^{\circ} \mathrm{C}\right)$ (Gráfica 2), producto de la intensa actividad microbiológica, particularmente de los actinomicetos (Tabla 3); dicha temperatura se mantuvo durante 50 días más.

En el día 245, cuando la humedad descendió del límite de $30 \%$, la temperatura se mantuvo alta $\left(48{ }^{\circ} \mathrm{C}\right)$ debida a la acción de los actinomicetos, en tanto que las bacterias se mantuvieron a un bajo nivel de actividad y los hongos no mostraron ninguna respuesta (Tabla 3). Posteriormente, entre los 285 y 300 días, la humedad siguió descendiendo hasta llegar finalmente a $27 \%$ y una temperatura de $42{ }^{\circ} \mathrm{C}$ (Gráfica. 2), periodo en el cual se registró la más alta población de actinomicetos en todo el ciclo de compostaje (Tabla 3).

El hecho de que la pila conservara la humedad durante varias semanas dentro del intervalo recomendable, fue una característica excepcional del compostaje de bagazo ya que solamente recibió agua de la lluvia y además se aplicaron volteos periódicos. La temperatura se mantuvo en el nivel termófilo $\left(>45^{\circ} \mathrm{C}\right)$ durante más de 270 días, lo cual no es común que suceda con la mayor parte de residuos que usualmente se compostan. 
Es probable que el mayor volumen de la pila haya favorecido las condiciones que permitieron conservar la humedad, ya que una pila de baja altura $(<1 \mathrm{~m})$ está más expuesta a secarse por efecto del aire y del calor (Ryckeboer et al., 2003).

\section{Dinámica de la temperatura}

En la Gráfica 2, se observa que la pila inició con una temperatura elevada $\left(62^{\circ} \mathrm{C}\right)$ debido a que el bagazo siempre llega muy caliente al sitio de compostaje $\left(\sim 70{ }^{\circ} \mathrm{C}\right)$ debido a que es cocido con vapor durante siete horas a $90{ }^{\circ} \mathrm{C}$. La gráfica de regresión muestra que la temperatura tiene una relación muy determinante con respecto al tiempo de compostaje $\left(\mathrm{R}^{2}=0.75\right)$. La temperatura más alta registrada durante todo el ciclo de compostaje fue de $67^{\circ} \mathrm{C}$ y ocurrió 15 días después del inicio del proceso debido seguramente a la intensa actividad de las bacterias (Tabla 3), dada la abundante disponibilidad de substancias fácilmente biodegradables tales como proteínas, almidón y azúcares residuales (12.3\%).

En términos generales, la mayor parte del tiempo la temperatura fluctuó en el rango termófilo óptimo entre 45 a $65^{\circ} \mathrm{C}$, sin embargo, no presentó la etapa mesófila inicial $\left(<45^{\circ} \mathrm{C}\right)$, típica del compostaje de residuos, y sólo una incipiente etapa mesófila final $\left(<45^{\circ} \mathrm{C}\right)$ a los 270 días (Bueno et al., 2008). A los 195 días, la temperatura disminuyó drásticamente a $49{ }^{\circ} \mathrm{C}$ cuando la pila presentó $40 \%$ de humedad, que es el nivel donde la velocidad de descomposición se reduce notoriamente (Liang et al., 2003), y terminó en $42{ }^{\circ} \mathrm{C}$ a los 300 días.

Los resultados de temperatura obtenidos en el presente estudio coincidieron con los registrados por Rodríguez et al. (2013), en el compostaje a gran escala del bagazo de agave con vinazas, aún cuando los autores aplicaron riegos periódicos con agua en dos pilas de composta de aproximadamente 30 toneladas cada una durante 154 días. La condición de altas temperaturas por tiempo prolongado de la pila de composta se puede explicar por lo citado por Ryckeboer et al. (2003), quienes mencionan que el calor generado por la actividad microbiana usualmente es retenido en la pila de compostaje por la capacidad autoaislante del material.

\section{Dinámica del pH}

El pH varió desde 4.3 en el primer muestreo, hasta un máximo de 8.9 en el día 245. La gráfica de regresión muestra que el $\mathrm{pH}$ se relaciona en gran medida con el tiempo de compostaje $\left(\mathrm{R}^{2}=\right.$ 0.79) (Gráfica 3). El pH más bajo coincidió, aproximadamente con las fases de mayor calentamiento, y por tanto, de mayor actividad microbiológica, particularmente de los actinomicetos (Tabla 3), lo cual propició la liberación de ácidos orgánicos (Cooperband, 2002). La utilización de los ácidos orgánicos en la actividad microbiana, la proteólisis y la mineralización de nitrógeno con liberación de amoníaco, durante el inicio de la fase termófila conducen a un incremento gradual del $\mathrm{pH}$ hasta alcanzar valores en torno a 8.5 (Moreno y Mormeneo, 2008).

\section{Dinámica de la conductividad eléctrica}

En la Gráfica 4 se observa que durante el compostaje, la conductividad eléctrica (CE) se elevó en dos ocasiones, primero, a los 15 días alcanzó $0.8 \mathrm{dS} / \mathrm{m}$, y después, a partir de los 245 días del compostaje ascendió otra vez hasta alcanzar finalmente $1.5 \mathrm{dS} / \mathrm{m}$. La gráfica de regresión muestra una muy clara tendencia de la CE a incrementarse sustancialmente en la fase final del proceso de compostaje como producto de la mineralización de los residuos orgánicos $\left(\mathrm{R}^{2}=0.86\right)$.

El primer incremento notable de la $\mathrm{CE}$ podría atribuirse a la intensa actividad bacteriana, mientras que el segundo al efecto ocasionado por fuerte actividad de los actinomicetos que contribuyeron a la reactivación de la mineralización del bagazo (Tabla 3). Yadav y Garg (2011) obtuvieron resultados similares en donde el incremento de la CE se debió a la liberación de diferentes iones minerales, tales como fosfatos, amonio $\mathrm{y}$ potasio.

\section{Correlación y niveles de significancia entre variables físicas y químicas del compostaje}

En el Tabla 2 se observa que la temperatura tiene una relación altamente significativa con los días de compostaje y la humedad $(\mathrm{p}<0.01)$ y lo mismo sucede entre la pérdida de humedad y el tiempo de compostaje. 
En tanto que varios factores se correlacionan significativamente $(\mathrm{p}<0.05)$ entre sí, por ejemplo: a) días de compostaje con el $\mathrm{pH}$ y la $\mathrm{CE}, \mathrm{b}) \mathrm{pH}$ con la humedad y la temperatura y c) CE con la humedad y la temperatura.

\section{Dinámica de la materia orgánica (MO) y relación $\mathrm{C} / \mathrm{N}$}

Las evaluaciones de materia orgánica y relación $\mathrm{C} / \mathrm{N}$ se realizaron hasta los 240 días y se obtuvieron los siguientes resultados:

Materia orgánica. En la Gráfica 5, se observa que entre los 70 a 135 días la MO llegó al nivel común para compostas 35 a $70 \%$ (Dougherty, 1999). Casi al final del ciclo (240 días), el contenido se redujo al nivel del $30 \%$, ligeramente por debajo del límite mínimo recomendado $(35 \%)$.

Relación C/N. La Gráfica 5 muestra que desde un principio la pila presentó un compostaje muy intenso ya que aún a pesar de la alta relación C/N inicial de 96.9 , se registró una alta temperatura promedio de $63{ }^{\circ} \mathrm{C}$ (Gráfica 2), y después de 15 días de iniciar el proceso la relación $\mathrm{C} / \mathrm{N}$ se redujo a 43 , es decir, una diferencia de $55.6 \%$ de reducción de $\mathrm{C} / \mathrm{N}$. Justamente a los 15 días la composta alcanzó 67 ${ }^{\circ} \mathrm{C}$, que fue la temperatura más alta registrada en todo el periodo de evaluación (Gráfica 2).

Esta enérgica respuesta al compostaje de bagazo contradice la recomendación de la literatura especializada en cuanto a que la relación $\mathrm{C} / \mathrm{N}$ ideal para que el compostaje se encuentra entre 25 y 35 (área sombreada de la Gráfica 5), lo que hace deducir que este residuo posee características muy particulares con respecto al resto de los desechos sólidos comunes.

Las causas del compostaje atípico de bagazo de agave podrían atribuirse a los siguientes factores:

1. Aumento de la superficie de contacto: la molienda de cabezas de agave que se transforman en bagazo hace más accesible el ataque de las enzimas microbianas.
2. Reblandecimiento por hidrotermólisis: el agua hincha la celulosa y hemicelulosas, las solubiliza más fácilmente, favorece su hidrólisis y reblandece la lignina (Harmsen et al., 2010), lo cual facilita la descomposición microbiana.

3. Efecto de los azúcares residuales como co-sustrato: la metabolización de la lignina requiere de un co-sustrato alternativo que sea fácilmente metabolizable y que pueda ser utilizado como fuente alterna de carbono y energía (Lucas et al., 2001), a este respecto, el análisis de azúcares residuales del bagazo de agave alcanzó el $12.3 \%$, que seguramente fue suficiente para activar de inmediato el proceso de compostaje.

\section{Dinámica de las bacterias}

En el Tabla 3 se observa que la mayor población de bacterias se incrementó desde 5.2 (día 0) hasta alcanzar 424.4 ufc x $10^{5} \mathrm{~g}^{-1}$ M.S. (día 15), que fue el máximo valor registrado durante el compostaje de bagazo, para después descender hasta 70.7 ufc x $10^{5} \mathrm{~g}^{-1}$ M.S. Posteriormente, se mantuvo en el rango entre 100 y 50 ufc x $10^{5} \mathrm{~g}^{-1}$ M.S. hasta 165 días, y por último, descendió hasta terminar en 28 ufc x $10^{5} \mathrm{~g}^{-1}$ M.S.

La dinámica de la población de bacterias se puede explicar, debido a que estas actúan mejor en $\mathrm{pH}$ entre $6-7.5$ y en ambientes húmedos (Rebollido et al., 2008), lo cual coincide con lo ocurrido durante el compostaje de bagazo, ya que en el momento de máxima actividad (15 días) el pH se ubicó en 5.8 y la humedad en $74.4 \%$. La reducción en el tamaño de la población de las bacterias se debe al agotamiento de hidratos de carbono de fácil descomposición, los cuales se van degradando en función de la complejidad de su estructura (Steger et al., 2005).

No obstante, los materiales carbonados más simples son los que se rompen inicialmente y sirven de sustrato para diversos microorganismos, por lo que se incrementa la biomasa microbiana en las etapas iniciales del proceso; mientras que, en etapas posteriores, los materiales restantes son más complejos y los microorganismos que los atacan son específicos y menos abundantes (Alexander, 2001). 


\section{Dinámica de los hongos}

La máxima actividad de hongos se registró durante los primeros 15 día de compostaje (Tabla 3), cuando la temperatura de la pila alcanzó los $67^{\circ} \mathrm{C}$. Se presentaron dos períodos consecutivos con máximo crecimiento poblacional los días 15 y 60 , lo cual pudo deberse al fenómeno de sucesión poblacional ya que diversos grupos de microorganismos se desarrollan en un ambiente específico durante un espacio de tiempo limitado (Dalzell et al., 2007). El segundo incremento de poblaciones de hongos fue más intenso el día $60\left(54{ }^{\circ} \mathrm{C}\right)$, lo cual contrastó con la disminución en la población de bacterias (Tabla 3), ya que al dejar el nicho que éstas tenían, lo ocuparon los hongos, proceso que también podría atribuirse a la llamada sucesión microbiana (Miller, 1993).

El $\mathrm{pH}$ registrado en el clímax de actividad de los hongos fue de 5.8 y 8.4, respectivamente, lo cual coincide con Moreno y Mormeneo (2008), quienes afirman que aunque los hongos prefieren $\mathrm{pH}$ ácido, algunos toleran un rango más amplio de $\mathrm{pH}$ que las bacterias, que puede oscilar entre 5.5 y 8 .

Después de la presencia de dos ciclos de máxima actividad, se observó un marcado descenso de poblaciones a partir del día 70 , mismo que continuó hasta alcanzar la total inactividad en el día 90 y así hasta el final del estudio. Este comportamiento probablemente fue resultado del efecto combinado de dos factores: 1) $\mathrm{pH}>7$ durante más del $90 \%$ del tiempo de compostaje (Nakasaki et al., 1985) (Gráfica 3), y 2) Efecto fungicida (y bactericida) de algunos géneros de actinomicetos, por ejemplo Streptomyces (Quiñones et al., 2016).

\section{Dinámica de los actinomicetos}

En el Tabla 3 se observa que la actividad de los actinomicetos durante el compostaje manifestó una actividad importante 15 días después del inicio del proceso. Esto se puede explicar por el hecho de que la pila había sido inoculada con composta madura, y seguramente contenía vestigios activos de esos organismos. Posteriormente, a medida que avanzó el compostaje, las colonias de actinomicetos fueron escalando gradualmente en número, con periodos de intermitencias de 60 días primero, y de 150 días al final.
La explicación a este fenómeno podría fundamentarse en los resultados obtenidos por Rebollido et al. (2008), quienes afirman que las diversas comunidades microbianas predominan durante las diferentes fases del compostaje y cada una se adapta a un ambiente particular, por lo que durante el compostaje, la composición de éstas se determina por varios factores como: temperatura, $\mathrm{pH}$, humedad, relación $\mathrm{C} / \mathrm{N}$, entre otros.

En este sentido, Steger et al., (2007) manifestaron haber encontrado también cambios en la composición de las especies de actinomicetos durante la fase termófila del compostaje a gran escala de desechos sólidos urbanos. Los actinomicetos termotolerantes (50$60{ }^{\circ} \mathrm{C}$ ) fueron detectados durante todo el proceso que duró 57 semanas, donde predominaron temperaturas entre 50 y $80{ }^{\circ} \mathrm{C}$, y sólo al final, se detectaron especies propias de la etapa mesófila. Los autores concluyeron que varios géneros de actinomicetos detectados en su investigación son capaces de degradar contaminantes y eventualmente podrían utilizarse en la biorremediación de suelos.

A este respecto, Velasco y Volke (2003) mencionan que la técnica del compostaje se ha usado con éxito en México para la biorremediación de suelos contaminados por pentaclorofenol (PCP), gasolinas e hidrocarburos totales de petróleo (HTP).

La fuerte dominancia de los actinomicetos en el proceso de compostaje registrada en el presente estudio coinciden con los resultados de Velasco et al., (2004) quienes establecen que los actinomicetos fueron el principal grupo responsable de la conversión de la materia orgánica en la etapa final del compostaje de residuos sólidos municipales y estiércol mezclado con paja de arroz, el cual se caracterizó por encontrarse en el rango termófilo con temperaturas variables entre 45 a $55{ }^{\circ} \mathrm{C}$. A este respecto, Tuomela et al. (2000) y Beffa (2002), sostienen que los actinomicetos son generalmente más tolerantes que los hongos a temperaturas entre moderadas y altas, así como a un $\mathrm{pH}$ elevado, y su número y diversidad de especies se incrementa marcadamente entre 50 y $60{ }^{\circ} \mathrm{C}$; de esta forma, los actinomicetos son organismos muy importantes en la degradación de la lignina durante las fases altas de temperatura. 
En la pila de composta, el número de colonias de actinomicetos se incrementó fuertemente a partir de los 245 días, a pesar de que el contenido de humedad fue de $32 \%$; posteriormente descendió hasta alcanzar $27 \%$ en el último registro (Gráfica 1). Este comportamiento se explica porque las células de los actinomicetos se caracterizan por tener una alta presión osmótica que sobrepasa a la solución de la composta y les permite la asimilación de humedad que es inaccesible a otros organismos (Mishustin, 1956). En tanto NRAES (2007) confirma que los actinomicetos prevalecen al final del compostaje cuando el nivel de humedad cae, el $\mathrm{pH}$ asciende y ya no existen compuestos fácilmente biodegradables.

El hecho de que en el compostaje de bagazo de agave proliferen notablemente los actinomicetos sobre las bacterias y los hongos, a través del tiempo, representa una valiosa importancia para la agricultura, ya que algunas especies poseen una actividad antimicrobiana sobre ciertos fitopatógenos; su modo de acción es mediante la producción de antibióticos, enzimas y otros compuestos bioactivos que inhiben la germinación y el crecimiento de algunos fitopatógenos en las plantas (Reyes et al. 2015). Cepas como Micromonospora spp., Streptomyces spp., Streptosporangium spp., y Thermobifida spp., fueron reportadas como las mejores para colonizar la rizósfera de las plantas y mostraron un alto potencial como agentes de biocontrol contra un amplio rango de hongos patógenos de las raíces (Franco-Correa et al., 2010). Su uso podría reducir la aplicación de agroquímicos tóxicos que ocasionan problemas ambientales para los microorganismos benéficos, flora y fauna nativa e incluso para la salud humana (Torres y Capote, 2004). Otro de los rasgos importantes de los actinomicetos es la producción de fitohormonas, tales como las auxinas, que favorecen el desarrollo de las plantas y por ello también se les considera como organismos promotores del crecimiento vegetal (Franco-Correa et al., 2008).

\section{Conclusiones}

A pesar de la alta relación C/N (96.9) del bagazo, el compostaje fue termófilo $\left(>45 \quad{ }^{\circ} \mathrm{C}\right)$ inmediatamente desde el inicio hasta los 270 días y finalizó con un corto periodo mesófilo $\left(<45{ }^{\circ} \mathrm{C}\right)$ propiciado por la reducción del contenido de humedad $(<30 \%)$.
Esta tendencia de temperatura es atípica con respecto al compostaje de la mayoría de desechos orgánicos y se atribuye a las características excepcionales del bagazo fresco: elevado contenido de humedad (82 \%) y temperatura $\left(65-70{ }^{\circ} \mathrm{C}\right)$ antes del iniciar el compostaje a causa de la previa cocción que produce reblandecimiento por hidrotermólisis, así como el alto contenido de azúcares residuales (12.3\%), los cuales activan una intensa actividad microbiana desde el comienzo del compostaje. La MO se mantuvo en general en el intervalo ideal (35-70\%), y la CE máxima final fue de $1.5 \mathrm{dS} / \mathrm{m}$, la cual es adecuada para usarse en cultivos sensibles a las sales. La mayor actividad de las bacterias y hongos se presentó hasta los 60 días y disminuyó progresivamente. Los actinomicetos fue el grupo más dominante sobre todo en las etapas finales del compostaje.

\section{Referencias}

Alexander R. (2001). Compost Utilization in Landscapes. En: Compost utilization in horticultural cropping systems. (P.J. Stoffela, and B.A. Kahn, Eds.). Lewis Publishers, Boca Raton, Florida, EUA. pp. 151-175.

Alonso M.S. y Rigal L. (1997). Caracterización y valorización del bagazo de Agave tequilana Weber de la Industria del tequila. Revista Chapingo, Serie Horticultura, México. 3(2), 3139.

AOAC (1984). Official methods of analysis. $14^{\mathrm{a}}$ ed. Association of Official Analytical Chemist, Washington, DC, EUA. 952 pp.

Beffa T. (2002). The composting biotechnology: a microbial aerobic solid substrate fermentation complex process. Compag Technologies International. Switzerland. $37 \mathrm{pp}$.

Bueno M.P., Díaz B.M.J. y Cabrera C.F. (2008). Factores que afectan el proceso de compostaje. En: Compostaje. (J. Moreno C., y R. Moral H., Eds.). Ediciones Mundi-Prensa. España. pp. 95109.

Cedeño, C.M. 1995. Tequila production. Critical Reviews in Biotechnology. 15(1):1-11.

CRT (2019). Estadísticas oficiales de consumo de agave para tequila y tequila $100 \%$ de agave de 2018. Consejo Regulador del Tequila [en línea]. http://www.crt.org.mx. 04.5.2019. 
Cooperband L. (2002). The art and science of composting. A resource for farmers and compost producers. Center for Integrated Agricultural Systems, University of Madison-Wisconsin, EUA. 14 pp.

CWMI (1996). Monitoring compost $\mathrm{pH}$. Cornell Waste Management Institute [en línea]. http:/compost.css.

cornell.edu/monitor/monitorph.html 07/07/2007.

Dalzell H.W., Biddlestone A.J., Gray K.R. y Thurairajan K. (2007). Soil management: compost production and use in tropical and subtropical environments. Daya Publishing House. India. 177 pp.

Dougherty M. (1999). Field guide to on-farm composting. National Resource, Agriculture and Engineering Service (NRAES). Ithaca, New York, EUA. 118 pp.

Franco-Correa, M. Quintana A Christian Suarez, C.D., Rodríguez, M.X. y Barea J.M. (2010). Evaluation of actinomycete strains for key traits related with plant growth promotion and mycorrhiza helping activities. Appl.Soil Ecol. 45, 209-217.

Golueke C.G. (1977). Biological processing: composting and hydrolysis. En: Handbook of solid waste management. (D.G. Wilson, Ed.). Van Nostrand Reinhold, New York, EUA. pp. 197-225.

Harmsen P.F.H., Huijgen W.J.J., BermúdezLópez L.M. y Bakker R.R.C. (2010). Literature review of physical and chemical pretreatment processes for lignocellulosics biomass. Food and Biobased Research. Energy Research Centre of the Netherlands. 49 pp.

INIFAP (2005). Potencial productivo agrícola de la Región Valles. Libro Técnico $\mathrm{N}^{\circ} 2$ [en línea]. http://www.oeidrus-

jalisco.gob.mx/municipal/potencial/RegionVall es.pdf 06.06.2016.

Iñiguez G., Fuentes F.J., Lange S.E. y Rowell R.M. (2007). Bagazo de agave como materia prima para la fabricación de tableros aglomerados. En: Obtención de materiales compuestos empleando polímeros naturales. (F.J. Fuentes T., J.A. Silva G. y J. Ramos Q., Eds). Universidad de Guadalajara, México. pp. 15-34.
Liang C., Das K.C. y McClendon R.W. (2003). The influence of temperature and moisture contents regimes on the aerobic microbial activity of a biosolid composting blend. Bioresour. Technol. 86,131-137.

Lucas R., Robles A.M., del Postigo A.G., García T., Pérez R. y Álvarez de C. G. (2001). Biodegradación de la celulosa y la lignina. Universidad de Jaén, España. 148 pp.

Miller G.L. (1959). Use of dinitrosalicylic reagent for determination of reducing sugar. Anal. Chem. 31(3), 426-428.

Miller F.C. (1993). Composting as a process based on the control of ecologically selective factors. En: Soil microbial ecology. (F.B. Metting Jr., Ed.). Marcel Decker, Inc. New York, EUA. pp. 515-543.

Minitab 17 (2015). Languaje Pack-español. Minitab® Inc. v.17.2.1. E.U.A.

Mishustin E.N. (1956). Microorganismos y fertilidad del suelo. En: Materia orgánica del suelo. Su naturaleza, propiedades y métodos de investigación. (M.M. Kononova, Ed.). Edición al castellano traducida por Enriqueta Bordas de Mután, Oikos-Tau, S.A., Ediciones, Vilassar del Mar, Barcelona, España. p. 166.

Moreno M. y Mormeneo S. (2008). Microbiología y bioquímica del proceso de compostaje. En: Compostaje. (C. Moreno, J. y R. Moral H., Eds.). Ediciones Mundi-Prensa, España. pp. 111-140.

Nakasaki K., Sasaki M., Shoda M. y Kubota H. (1985). Change in microbial during thermophilic composting of sewage sludge with reference to $\mathrm{CO}_{2}$ evolution rate. Appl. Environ. Microbiol. 49(1), 37-41.

NRAES (2007). Composting manure. What's going on in the dark? Manure Management Information Sheet, Number 1. Natural Resource, Agriculture and Engineering Service, USDA, Ithaca, New York, EUA. 8 p.

PROFOA (2010). Análisis químico del bagazo de agave. Producción y Fomento de Agave, S. de R.L. y Tequila Sauza, S.A. Reporte interno. 15 p. 
Quiñones-Aguilar E., Evangelista-Martínez Z. y Rincón-Enríquez G. (2016). Los actinomicetos y su aplicación biotecnológica. Elementos: ciencia y cultura. BUAP. 101(23), 59-64.

Rebollido R., Martínez J., Aguilera Y., Melchor K., Koerner I. y Stegmann R. (2008). Microbial population during composting process of organic fraction of municipal solid waste. Appl. Ecol. Environ. Res. 6(3):61-67.

Reyes T., A., Rincón E., G, López P., L., Evangelista M., Z. Quiñones A., Quiñones A., E. (2015). Lucha entre microbios: una herramienta para el control de enfermedades de plantas. Revista Digital Universitaria, UNAM, México. 16(11), 2-15.

Robert F. M. (1990). Impact of environmental factors on populations of soil microorganisms. Am. Biol. Teach. 52: 364-369.

Rodríguez R., Quintero R., Alcántar G., Ordaz V. y Volke V. (2004). Dinámica y cuantificación de de grupos microbianos en compost y vermicompost de bagazo de agave tequilero. Terra Latinoam. 23, 97-104.

Rodríguez R., Jiménez J.F., del Real J.I., Salcedo E., Zamora J.F. e Íñiguez G. (2013). Utilización de subproductos de la industria tequilera. Parte 11. Compostaje de bagazo de agave crudo y biosólidos provenientes de una planta de tratamiento de vinazas tequileras. Rev. Int. Contam. Ambie. 29 (4), 303-313.

Ryckeboer J., Mergaert J., Coosemans J., Deprins K. y J. Swing (2003). Microbiological aspects of biowaste during composting in a monitoring compost bin. J. Appl. Microbiol. 94, 127-137.

Steger K., Eklind Y., Olsson J. y Sundh I. (2005). Microbial community growth and utilization of carbon constituents during thermophilic composting at different oxygen levels. Microb. Ecol. 50, 163-171.

Steger K., Sjögren Å.M., Jarvis Å., Jansson J.K. y Sundh I. (2007). Development of compost maturity and actinobacteria population during full-scale composting of organic household waste. J. Appl. Microbiol. 103(2), 487-498.
Torres, D. y Capote, T. (2004). Agroquímicos un problema ambiental global: uso del análisis químico como herramienta para el monitoreo ambiental. Revista Ecosistemas, España. 13(3), $2-6$.

Tuomela M, Vikman M., Hatakka A. y Itävaara M. (2000). Biodegradation of lignin in a compost environment: a review. Bioresour. Technol. 72(2000), 169-183.

Velasco J.A. y Volke T.L. (2003). El composteo: una alternativa tecnológica para la biorremediación de suelos en México. Gaceta Ecológica, SEMARNAT, México. 66, 41-53.

Velasco J., Figueroa B., Ferrera R., Trinidad A. y Gallegos J. (2004). $\mathrm{CO}_{2}$ y dinámica de poblaciones microbianas en compostas de estiércol y paja con aireación. Terra Latinoam. 22(3), 307-316.

Wollum A. G. (1982). Cultural methods for soil microorganisms. En: Methods of soil analysis. Agronomy 9. (C.A. Black, Ed.). Am. Soc. Agr. Madison, Wisconsin, EUA. Part 2, pp. 781-802.

Yadav A. y Garg V.K. (2011). Recycling of organic wastes by employing Eisenia fotida. Bioresour. Technol. 102 (3), 2874-2880.

\section{Anexos}

\begin{tabular}{|l|c|}
\hline \multicolumn{1}{|c|}{ Parámetros } & Composición \\
\hline Humedad \% & 90.04 \\
\hline $\mathrm{pH}$ & 4.72 \\
\hline Materia orgánica $(\%, \mathrm{MS})$ & 90.04 \\
\hline Cenizas $(\%, \mathrm{BS})$ & 9.96 \\
\hline Carbono orgánico total $(\%, \mathrm{MS})$ & 52.35 \\
\hline Nitrógeno total $(\%, \mathrm{MS})$ & 0.54 \\
\hline Relación C/N & 96.94 \\
\hline Conductividad eléctrica $\left(\mathrm{mS} \mathrm{cm}^{-1}\right)$ & 1.43 \\
\hline Fósforo $(\%, \mathrm{MS})$ & 0.04 \\
\hline Potasio $(\%, \mathrm{MS})$ & 0.15 \\
\hline Calcio $(\%, \mathrm{MS})$ & 3.31 \\
\hline Magnesio $(\%, \mathrm{MS})$ & 0.21 \\
\hline
\end{tabular}

Tabla 1 Composición química del bagazo de agave tequilero

\begin{tabular}{|c|c|c|c|c|c|}
\hline & & Días & $\mathrm{pH}$ & $\mathrm{CE}$ & Humedad \\
\hline pH & $\begin{array}{l}\mathrm{r} \\
\mathrm{p}\end{array}$ & $\begin{array}{c}0.54 \\
0.031 *\end{array}$ & & & \\
\hline CE & $\begin{array}{l}\mathrm{r} \\
\mathrm{p}\end{array}$ & $\begin{array}{c}0.517 \\
0.040 *\end{array}$ & $\begin{array}{l}0.096 \\
0.722\end{array}$ & & \\
\hline Humedad & $\begin{array}{l}\mathrm{r} \\
\mathrm{p}\end{array}$ & $\begin{array}{c}-0.986 \\
0.000^{* *}\end{array}$ & $\begin{array}{l}-0.528 \\
0-035^{*}\end{array}$ & $\begin{array}{l}-0.510 \\
0.044 *\end{array}$ & \\
\hline Temperatura & $\begin{array}{l}\mathrm{r} \\
\mathrm{p}\end{array}$ & $\begin{array}{l}-0.8010 \\
0.000^{* *}\end{array}$ & $\begin{array}{l}-0.525 \\
0.037 * \\
\end{array}$ & $\begin{array}{l}-0.568 \\
0.022 * \\
\end{array}$ & $\begin{array}{c}0.807 \\
0.000 * * \\
\end{array}$ \\
\hline
\end{tabular}

Tabla 2 Correlación y niveles de significancia entre variables físicas y químicas del compostaje

CRESPO-GONZÁLEZ, Marcos Rafael, RODRÍGUEZ-MACÍAS, Ramón, GONZÁLEZ-EGUIARTE, Diego Raymundo y CANALE-GUERRERO, Alejandro. Características físico-químicas y microbiológicas del compostaje de bagazo de agave tequilero a escala industrial. Revista de Energía Química y Física. 2019 


\begin{tabular}{|c|c|c|c|}
\hline $\begin{array}{c}\text { Días de } \\
\text { muestreo }\end{array}$ & $\begin{array}{c}\text { Bacterias } \\
\text { ufc } \times 10^{5} \mathrm{~g}^{-1} \\
(\text { M.S.) }\end{array}$ & $\begin{array}{c}\text { Hongos } \\
\text { ufc x } 10^{1} \mathrm{~g}^{-} \\
{ }^{1} \text { (M.S.) }\end{array}$ & $\begin{array}{l}\text { Actinomicetos } \\
\text { ufc } \times 10^{4} \mathrm{~g}^{-1} \\
\text { (M.S.) }\end{array}$ \\
\hline 0 & $5.2 \pm 1.6$ & $0.2 \pm 0.4$ & 0.0 \\
\hline 15 & $424.4 \pm 21.6$ & $78.4 \pm 6.8$ & $64.7 \pm 5.4$ \\
\hline 30 & $70.7 \pm 1.6$ & $3.26 \pm 0.5$ & $3.8 \pm 0.5$ \\
\hline 45 & $29.9 \pm 4.6$ & $7.93 \pm 1.0$ & $1.4 \pm 0.6$ \\
\hline 60 & $106.6 \pm 3.0$ & $151.1 \pm 16.3$ & $11.8 \pm 1.8$ \\
\hline 75 & $38.6 \pm 2.3$ & $22.2 \pm 1.2$ & $66.46 \pm 2.7$ \\
\hline 90 & $41.1 \pm 7.5$ & $0.8 \pm 0.3$ & $60.6 \pm 2.9$ \\
\hline 105 & $.6 \pm 3.4$ & $0.4 \pm 0.1$ & $22.5 \pm 2.0$ \\
\hline 120 & $53.6 \pm 4.2$ & $0.93 \pm 0.5$ & $91.7 \pm 3.5$ \\
\hline 135 & $22.0 \pm 2.3$ & $0.06 \pm 0.8$ & $149.8 \pm 9.1$ \\
\hline 150 & $59.73 \pm 6.2$ & $0.06 \pm 0.9$ & $118.4 \pm 9.1$ \\
\hline 165 & $52.2 \pm 1.9$ & 0.0 & $99.9 \pm 5.5$ \\
\hline 195 & $12.0 \pm 2.1$ & 0.0 & $62.0 \pm 3.3$ \\
\hline 245 & $22.0 \pm 1.9$ & 0.0 & $69.0 \pm 2.9$ \\
\hline 285 & $41.0 \pm 2.2$ & 0.0 & $150.0 \pm 9.4$ \\
\hline 300 & $28.0 \pm 4.3$ & 0.0 & $154.0 \pm 15.3$ \\
\hline
\end{tabular}

Tabla 3 Dinámica poblacional de bacterias, hongos y actinomicetos cuantificados durante el compostaje del bagazo de agave tequilero

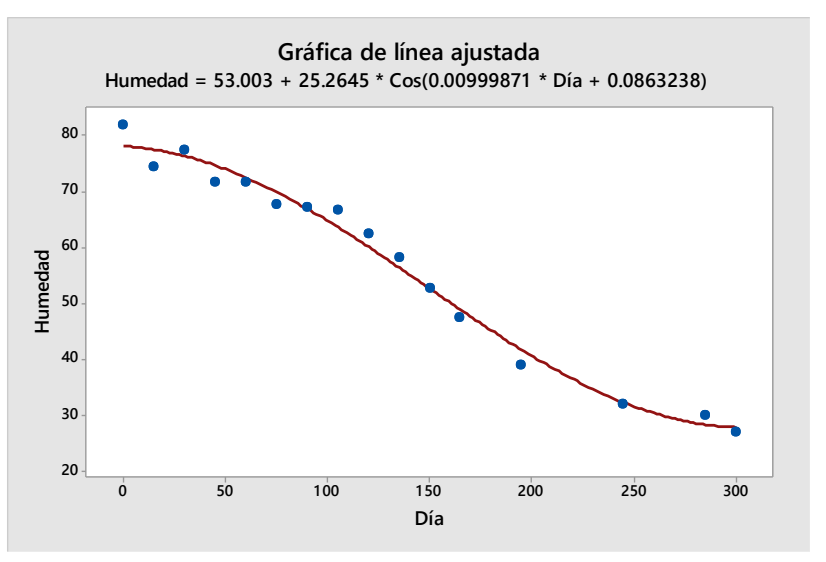

Gráfica 1 Relación entre la humedad y los días transcurridos $\left(\mathrm{R}^{2}=0.9849\right)$

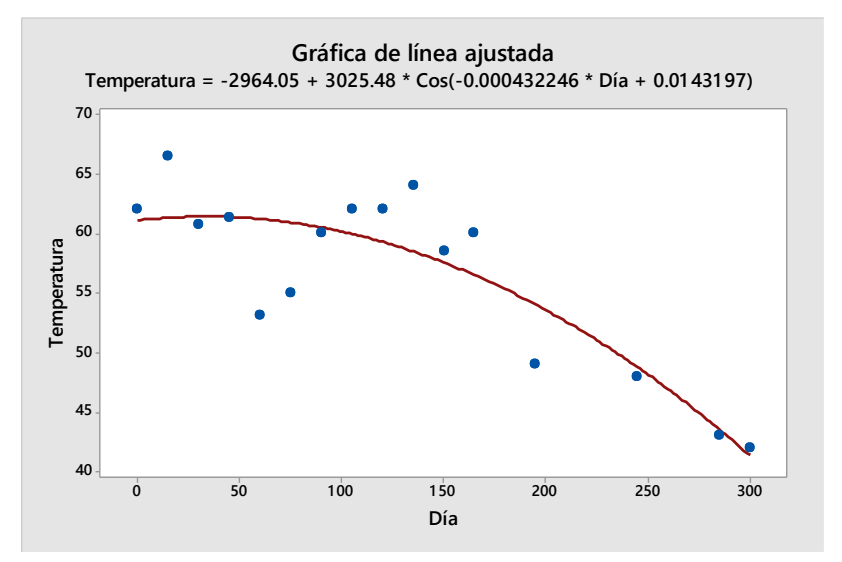

Gráfica 2 Relación entre la temperatura y los días transcurridos $\left(\mathrm{R}^{2}=0.7504\right)$

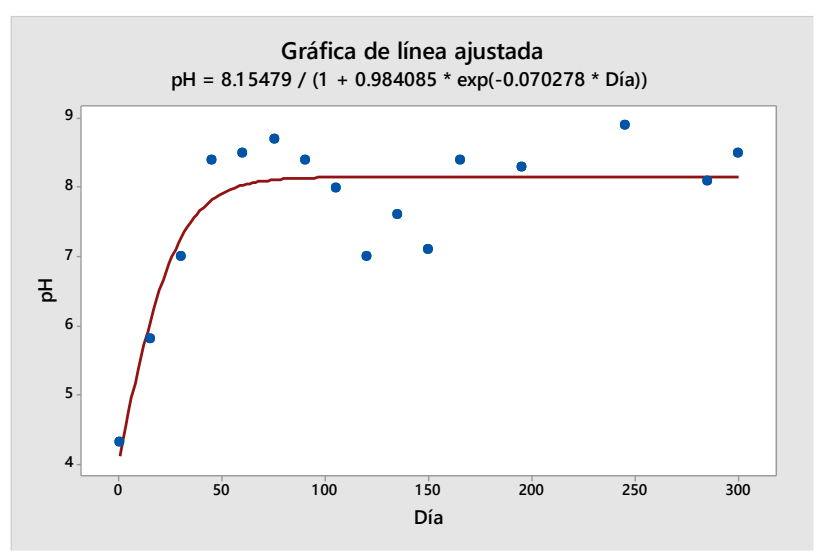

Gráfica 3 Relación entre el pH y los días transcurridos $\left(\mathrm{R}^{2}=0.7907\right)$

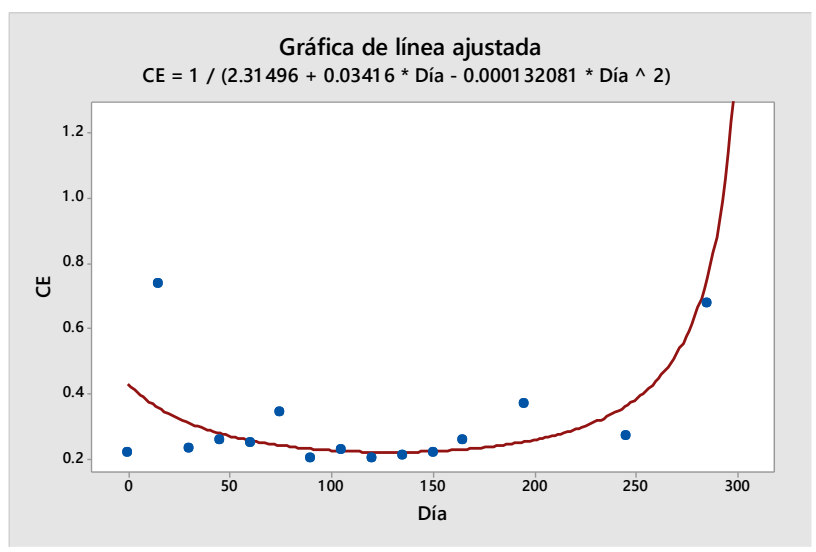

Gráfica 4 Relación entre la CE y los días transcurridos $\left(R^{2}=0.8624\right)$

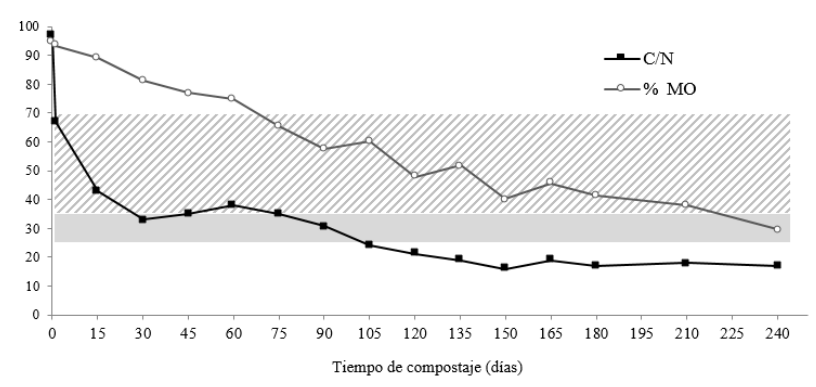

Gráfica 5 Valores de materia orgánica (MO) y relación $\mathrm{C} / \mathrm{N}$ durante el proceso de compostaje 